\section{OPEN ACCESS}

Edited by:

Vasu D. Appanna,

Laurentian University, Canada

Reviewed by:

Christopher Auger,

Sunnybrook Health Sciences Centre,

Canada

Xiaohui Gao

School of Medicine, Yale University,

United States

*Correspondence:

Mosharraf H. Sarker

m.sarker@tees.ac.uk

Specialty section:

This article was submitted to

Molecular Medicine,

a section of the journal

Frontiers in Cell and Developmental

Biology

Received: 21 April 2020

Accepted: 14 July 2020

Published: 30 July 2020

Citation:

Nanjundaiah YS, Wright DA,

Baydoun AR, Khaled Z, Ali Z, Dean P and Sarker MH (2020) Modulation

of Macrophage Function by

Lactobacillus-Conditioned Medium.

Front. Cell Dev. Biol. 8:723.

doi: 10.3389/fcell.2020.00723

\title{
Modulation of Macrophage Function by Lactobacillus-Conditioned Medium
}

\author{
Yashaswini Seenappanahalli Nanjundaiah ${ }^{1}$, David A. Wright ${ }^{1}$, Anwar R. Baydoun ${ }^{2}$, \\ Zahangir Khaled ${ }^{3}$, Zulfiqur Ali', Paul Dean ${ }^{1}$ and Mosharraf H. Sarker ${ }^{1 *}$
}

${ }^{1}$ School of Health and Life Sciences, Teesside University, Middlesbrough, United Kingdom, ${ }^{2}$ Faculty of Health and Life Sciences, De Montfort University, Leicester, United Kingdom, ${ }^{3}$ Pediatric Gastroenterology, College of Medicine at Peoria, University of Illinois, Peoria, IL, United States

Probiotics are used as microbial food supplements for health and well-being. They are thought to have immunomodulatory effects although their exact physiological mechanism of action is not clear. This study investigated the influence of probiotic Lactobacillus rhamnosus GG conditioned media (LGG-CM) on macrophage phagocytosis of non-pathogenic Escherichia coli HfrC. The gentamicin protection assay was used to study the bacterial killing phases of phagocytosis. Macrophages coincubated with $E$. coli for an hour allowed them to ingest bacteria and then the rate of $E$. coli killing was monitored for up to 300 min to determine the killing or digestion of the bacteria by recovering them from the macrophage lysate. We found that the LGGCM significantly increased the bacterial killing by approximately 6-fold when compared with that of controls. By contrast, this killing process was found to be associated with enhanced free radical production via the activation of NADPH oxidase, stimulated by the LGG conditioned medium. We also found that the conditioned medium had small effect on nitric oxide (NO) generation, albeit to a lesser extent. This work suggests that LGG-CM may play an important role in suppressing the total microbial load within the macrophages and hence, the extent to which pro-inflammatory molecules such as free radicals and $\mathrm{NO}$ are generated. The modulation of inflammation-promoting signals by LGG-CM may be beneficial as it modulates bacterial killing, and thereby prevents any collateral damage to host.

Keywords: Lactobacillus rhamnosus GG, macrophage, free radicals, phagocytosis, nitric oxide

\section{INTRODUCTION}

There is considerable interest in the role of probiotic bacteria in the modulation of human health and immune function (Yan and Polk, 2012). Species of lactic acid bacteria have been suggested to promote host innate immune function by influencing activity of phagocytic cells and modulating pathogen-induced inflammatory responses (Donnet-Hughes et al., 1999; Gill et al., 2001; Kotzamandis et al., 2010; Marranzino et al., 2012). Daily ingestion of probiotic supplements has also been shown to enhance innate immune functions by significantly increasing the number of phagocytic cells and IgA+ antibody levels in the blood (Berman et al., 2006; Galdeano et al., 2011).

Regulating phagocytic cell activity by probiotics may enhance the ability to engulf and kill harmful bacteria which is an important and highly conserved innate immune mechanism carried out by phagocytes such as macrophages and neutrophils. Phagocytosis follows a 
complex series of steps starting with the recognition and ingestion of the microbe, and formation of a phagosome where the microbe is eventually killed. Immunological recognition of microorganisms by phagocytes is followed by a series of biochemical events, producing a plethora of microbicidal agents including reactive oxygen species (ROS), nitric oxide (NO), and other reactive nitrogen species (RNS) and lytic enzymes which contribute to bacterial death (Flannagan et al., 2009).

While the health benefits of probiotics are becoming more evident, little is known of their underlying mechanisms of action. Moreover, current literature on their role in regulating phagocytosis have mostly looked at either the uptake of total number of particles or microbes, or the upregulation of oxidative activities of the cells when exposed to pathogen. There is limited literature on their role in the digestion or killing phases of phagocytosis (Yan and Polk, 2002; Vincenti, 2010). The aim of this study therefore was to investigate the effect of Lactobacillus on the killing phases of phagocytosis of Escherichia coli by mouse macrophages. The probiotic bacterium Lactobacillus rhamnosus GG (LGG), an extensively studied and widely used probiotic strain of human origin, was investigated as it has been shown to enhance phagocytic activity (Pelto et al., 1998) and stimulate antibody production (Kaila et al., 1992). Clinically, Lactobacillus strains of probiotics have also been reported to reduce diarrheal illness caused by intestinal pathogens (Nixon et al., 2012). Additionally, there is evidence that secretory components of Lactobacillus may also exert a beneficial effect on host immune activities (Rudin and Lundell, 2012; Yoda et al., 2012; Villena and Kitazawa, 2014). We have therefore investigated conditioned medium obtained from cultures of LGG and examined the digestion and degree of killing of $E$. coli induced by free radicals during phagocytosis.

\section{MATERIALS AND METHODS}

\section{Macrophage and Bacterial Culture}

The murine macrophage cell line J774A.1 was acquired from the American Type Culture Collection (ATCC) and used in all macrophage assays. Cells were cultured in Dulbecco's modified Eagle medium (DMEM; Gibco) with high glucose, supplemented with $10 \%$ FBS and $100 \mu \mathrm{g} / \mathrm{mL}$ penicillin/streptomycin (Sigma) and incubated in a humidified incubator at $37^{\circ} \mathrm{C}$ and $5 \%$ $\mathrm{CO}_{2}$. Macrophages were seeded into a 24-well plate at $5 \times 10^{5}$ cells/well. LGG was grown from commercially available Culturelle ${ }^{\circledR}$ tablets in de Man, Rogosa and Sharpe (MRS) broth. The Gram-negative bacterium E. coli strain HfrC, obtained from the National Collection of Industrial, Food and Marine Bacteria (NCIMB, United Kingdom), was used in all gentamycin protection assays following overnight growth in Luria-Bertani (LB) broth (Oxoid).

\section{Production of Lactobacillus rhamnosus GG Conditioned Media}

The Lactobacillus rhamnosus GG Conditioned Media (LGG-CM) was prepared as described previously (Nanjundaiah et al., 2016). In brief, under sterile conditions, a capsule of LGG Culturelle ${ }^{\circledR}$ was inoculated into $100 \mathrm{ml}$ of MRS broth and incubated for $24 \mathrm{~h}$ at $37^{\circ} \mathrm{C}$ with oscillation at $150 \mathrm{rpm}$ to early stationary phase. The LGG culture was then centrifuged for $10 \mathrm{~min}$ at $10,000 \times g$ and the supernatant discarded. The pellet was resuspended in $50 \mathrm{ml}$ DMEM and incubated for a further $24 \mathrm{~h}$ at $37^{\circ} \mathrm{C}$ with oscillation at $150 \mathrm{rpm}$. Cell-free supernatant was obtained by centrifugation for $10 \mathrm{~min}$ at $10,000 \mathrm{rpm}$ and filtered through $0.22 \mu \mathrm{m}$ filters. The supernatant was then aliquoted into small microfuge tubes and stored at $-20^{\circ} \mathrm{C}$ for further use. For each replica experiment, different batches of LGG-CM were prepared.

\section{Macrophage Viability Assay}

Macrophage viability was monitored by the mitochondrialdependant 3-(4,5-dimethyl-2-thiazyl)-2,5-diphenyl-2H-tetrazolium bromide (MTT) reduction assay. This test is based on the cleavage of the tetrazolium salt MTT to yield a blue formazan dye in viable cells. J774 macrophages $\left(1 \times 10^{5}\right.$ cells $\left./ \mathrm{mL}\right)$ were seeded $4 \mathrm{~h}$ prior to the assay in 96-well plates. LGG-CM was added to the cells at dilutions of 10,75 , and $100 \%$ with or without LPS $(20 \mu \mathrm{g} / \mathrm{ml})$ and incubated for 6 or $24 \mathrm{~h}$. MTT solution (5 $\mathrm{mg} / \mathrm{mL}$; Sigma) was prepared and added to each well according to manufacturer's instructions. The $\mathrm{A}_{550}$ was measured using a ELx 800 microplate reader (Bio-Tek) and $\%$ cytotoxicity was determined relative to control (untreated) cells. Lipopolysaccharide (LPS) from E. coli O111:B4 (purchased from Sigma) was used as a positive control for evaluation of macrophage activation.

\section{Experiments Investigating Antimicrobial Properties of LGG-CM}

To determine whether the LGG-conditioned medium demonstrated antibacterial properties within the specified time frame of our experiments, $E$. coli $\mathrm{HfrC}$ was grown overnight in $\mathrm{LB}$ broth at $37^{\circ} \mathrm{C}$ with shaking. A $1 \mathrm{ml}$ sample of $E$. coli culture was centrifuged and the pellet was carefully washed with PBS followed by DMEM and resuspended in $1 \mathrm{ml}$ of DMEM devoid of penicillin/streptomycin. This was diluted 1:50 in $1 \mathrm{ml}$ of varying concentrations of LGG-CM (5, 10, and 75, and 100\% LGG-CM, $\mathrm{pH} 7.4 \pm 0.2$ ) for 6 or $24 \mathrm{~h}$, after which, the bacteria was serially diluted and plated onto nutrient agar plates and colony forming (CFU) were counted.

\section{Monitoring Macrophage Killing of Intracellular E. coli}

Macrophages were grown in 24-well plates at $5 \times 10^{5}$ cells per well and incubated with E. coli in the presence of DMEM alone (control) or with LPS $(20 \mu \mathrm{g} / \mathrm{mL})$, LGG conditioned medium (LGG-CM; 10, 75, and 100\%) or a combination of both. An E. coli multiplicity of infection (MOI) of 50:1 was used for all experiments. Following an uptake period of $60 \mathrm{~min}$, gentamicin (200 $\mu \mathrm{g} / \mathrm{mL}$ ) was added for $15 \mathrm{~min}$ to kill all extracellular bacteria. Cells were washed with sterile PBS and incubated in DMEM containing a low inhibitory dose of gentamicin $\left(20 \mu \mathrm{g} \mathrm{ml}^{-1}\right)$. Cells were incubated for an indicated time period after which the macrophages were washed, lysed in $0.1 \%(\mathrm{v} / \mathrm{v})$ triton-X 100 and the released bacteria were resuspended and 
serially diluted, before being enumerated by CFU counts on nutrient agar plates. Time course experiments were performed every $40 \mathrm{~min}$ and data were fitted to killing curve using the equation $\mathrm{a}=\mathrm{a}^{0} \mathrm{e}^{-k t}$.

For inhibitor studies, macrophages were plated at a cell density of $5 \times 10^{5}$ cells $/ \mathrm{mL}$ and pre-treated with different inhibitors including $100 \mu \mathrm{M}$ L-NMMA (inhibitor of nitric oxide synthase), $100 \mu \mathrm{M}$ apocynin (NADPH oxidase inhibitor) or a combination of $100 \mu \mathrm{M}$ L-NMMA plus apocynin for $1 \mathrm{~h}$. Cell permeable forms of superoxide dismutase and catalase fused to polyethylene glycol (Sigma) were used to scavenge free radical during the assay. After pre-treatment the inhibitors were removed and cells were washed with PBS prior to the gentamycin protection assay (described above).

\section{Staining and Visualizing Live and Dead Intracellular Bacteria}

Macrophages were cultured as described above using glass bottom culture dishes for imaging. An overnight culture of E. coli was washed and labeled with $0.01 \%(\mathrm{w} / \mathrm{v})$ acridine orange for $45 \mathrm{~s}$. The stained cells were then washed 3 times with PBS and added (50:1) to the macrophages and incubated for $60 \mathrm{~min}$. After the coincubation period, cells were washed once with prewarmed PBS and extracellular bacteria were killed by gentamicin treatment. For monitoring bacterial digestion, images were taken at 15-300 min after a coincubation period of $60 \mathrm{~min}$ after which $0.05 \%$ (w/v) crystal violet dissolved in PBS was added to the cells to quench any extracellular fluorescence. Images were taken using Open Lab software and analyzed using Image Hopper 2 (Samsara research, United Kingdom). Crystal violet does not penetrate intact macrophage membranes and therefore does not quench the fluorescence of intracellular bacteria. The viable ingested bacteria appear green and dead bacteria appear red (Takao et al., 1996).

\section{ROS Detection Using a Microplate Reader}

Accumulation of intracellular ROS produced by J774 murine macrophages in 96 well tissue culture plates was measured using 2,7-dichlorofluorescein diacetate $\left(\mathrm{H}_{2} \mathrm{DCFDA}\right)$ and a microplate reader (Biotek). After removing the culture medium, the cells were washed once with pre-warmed PBS. Macrophages were then loaded with fresh medium containing $5 \mu \mathrm{M} \mathrm{H}_{2}$ DCFDA for $45 \mathrm{~min}$ at $37^{\circ} \mathrm{C}$ in $5 \% \mathrm{CO}_{2}$ in a humidified cell culture incubator. The dye solution was then removed and cells again carefully washed twice with pre-warmed PBS. The fluorescence measurements were taken every $2 \mathrm{~min}$ approximately for $280 \mathrm{~min}$ to monitor ROS production. The fluorescence was measured at $485 \mathrm{~nm}$ excitation and $528 \mathrm{~nm}$ emissions.

\section{ROS Detection Using Fluorescence Microscopy}

Fluorescence imaging of intracellular ROS in macrophages was detected using $\mathrm{H}_{2}$ DCFDA with a Nikon Eclipse TE2000U fluorescence microscope. Macrophages were scraped, counted and $1 \mathrm{ml}$ of macrophage culture added to small Petri dishes containing glass coverslips and incubated overnight in a humidified tissue culture incubator at $37^{\circ} \mathrm{C}$ and $5 \%$ carbon dioxide. On the day of the experiment, the media was replaced with media containing $5 \mu \mathrm{M} \mathrm{H}_{2}$ DCFDA. The cells were then left in the cell culture incubator for $45 \mathrm{~min}$, washed three times with phosphate buffered saline and fresh prewarmed phenol red free DMEM was added. The cover slip was removed and attached to the bottom of the imaging chamber (macrophage affixed side facing up) before the medium was added onto the chamber. The chamber was then placed under an inverted microscope where a bright field filter was used to focus the cells prior to the fluorescence imaging using Improvision Open lab software. A single channel heater controller (model TC-324B, Harvard Apparatus, United Kingdom) was used to control the temperature at $37^{\circ} \mathrm{C}$. Fluorescence images of ROS were captured in control and LPS and LGG treated cells at various time periods. Images were captured at excitation and emission wavelength of $495 \mathrm{~nm}$ and $520 \mathrm{~nm}$. The images were saved as tiff files and finally analyzed using Image Hopper2 software (Samsara Research, United Kingdom).

\section{Western Blot Analysis Expression}

Lysates for Western blot analysis were prepared from cells as follows. Total cell protein was determined using bicinchoninic acid (BCA) reagents following the manufacturer's instructions. Standard SDS-PAGE was performed and proteins were then transferred onto a polyvinylidene difluoride (PVDF) membrane and detected with either polyclonal anti-gp91phox (Santa Cruz, SC130543) or p47 phox (Santa cruz, SC17845) antibodies. $\beta$-actin was used as a loading control using an anti- $\beta$-actin antibody. Goat-anti mouse IgG (Santa Cruz, SC-2005) antibody was used as a secondary antibody conjugated with horseradish peroxidase. Bands were visualized by enhanced chemiluminescence detection using Clarity reagent (Biorad).

\section{Nitrite Determination by Greiss Assay}

Nitrite quantification was carried out using the Griess assay as described previously (Sun et al., 2003). Briefly, $100 \mu l$ of sample (cell culture medium) was incubated for $15 \mathrm{~min}$ in the dark at room temperature with $100 \mu$ l Griess reagent [1:1 ratio of $1 \%$ sulfanilamide in $10 \%$ orthophosphoric acid (reagent 1) and $0.2 \%$ napthylethylenediamine in $\mathrm{dH}_{2} \mathrm{O}$ (reagent 2)]. Absorbance was read at $540 \mathrm{~nm}$ on a fluorescent plate reader.

\section{Statistical Analysis}

All experiments were performed a minimum of three times, with three replicates in each. One-way analysis of variance (ANOVA) and post hoc Tukey's test was performed on datasets with critical values set at $p<0.05$ with GraphPad Prism software (GraphPad Software, Inc., San Diego, CA, United States). To determine the rate of exponential decrease for bacterial killing, data were fitted to a killing curve using the equation $\mathrm{a}=\mathrm{a}^{0} \mathrm{e}^{-k t}$. 


\section{RESULTS}

\section{Effect of Lactobacillus rhamnosus Conditioned Medium on Macrophage Viability}

The release of immuno-modulatory compounds by the probiotic bacterium LGG was tested by growing the bacterium to a specific optical density in serum-free DMEM and testing the properties the LGG DMEM conditioned medium (LGG-CM). However, it was first necessary to test whether the LGG-CM had any biocidal activities on J774 macrophages which was determined by the MTT assay at $6 \mathrm{~h}$ and $24 \mathrm{~h}$ following post-incubation. LGG-CM had no significant effect on macrophage viability, even when used undiluted (100\%) suggesting any released LGG components or LPS were not toxic to the macrophages (Figure 1A). Incubation of macrophages with LGG-CM, LPS, E. coli whole cells alone or a combination of these, showed little effect on macrophage viability (Figure 1A; $p>0.05$ ) within the time frame. Therefore, under the experimental conditions used throughout this study, macrophage viability did not appear to be adversely affected.

A
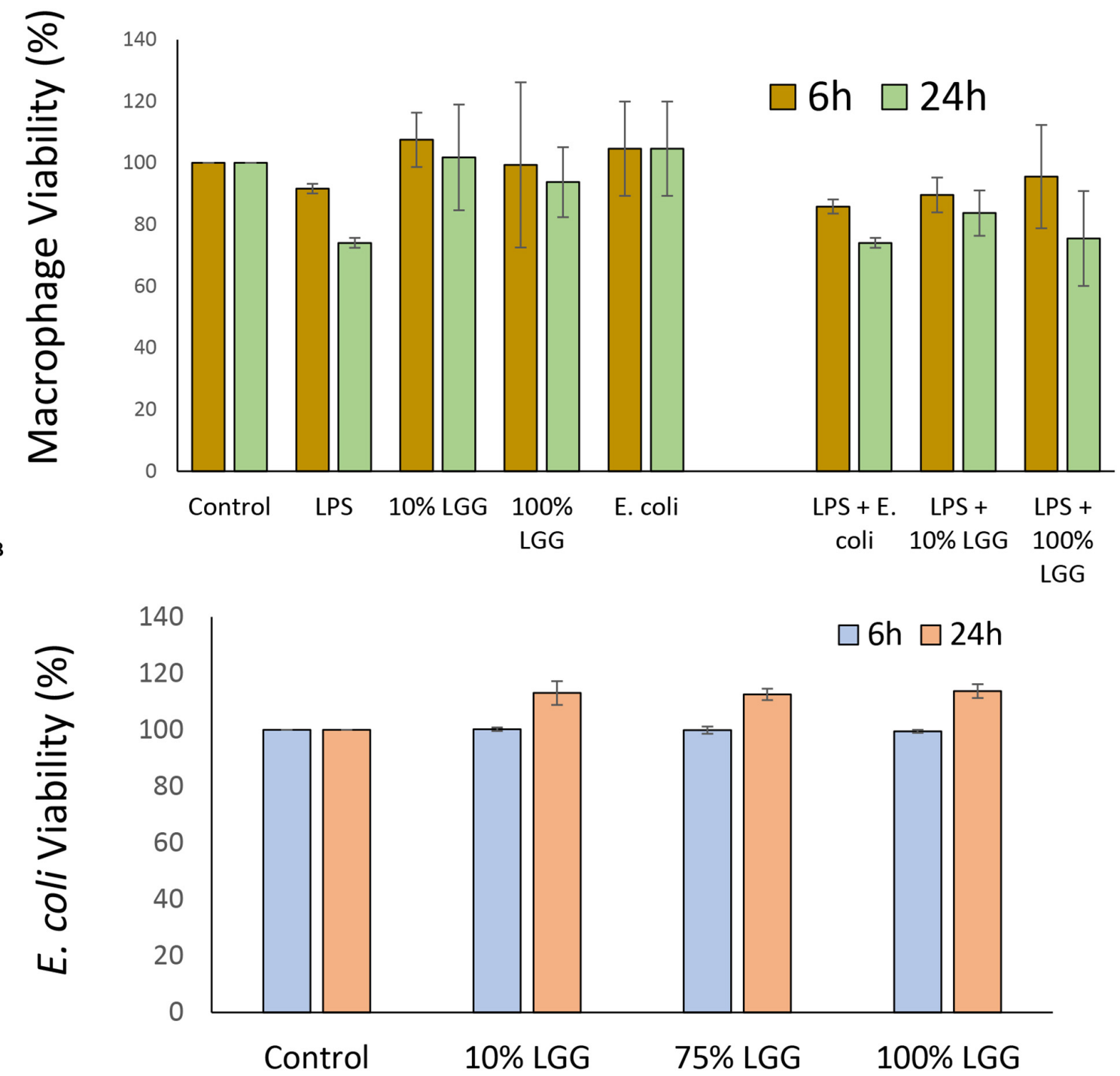

FIGURE 1 | Effect of LGG conditioned medium on macrophage and E. coli viability. (A) Macrophages were grown in 24 well plates and exposed to LPS, LGG conditioned medium (LGG-CM), or E. coli cells for $6 \mathrm{~h}$ (olive), or $24 \mathrm{~h}$ (light green). Cell viability was assessed by MTT reduction. LPS concentration was $20 \mu \mathrm{g} / \mathrm{ml}$; LGG conditioned medium was $10 \%$ or $100 \%$. Control was no additions. (B) Viability of $E$. coli HfrC after incubation with LGG supernatant for $6 \mathrm{~h}$ (light blue) and $24 \mathrm{~h}$ (orange). Recovered colony forming units (CFU) were determined. Control cells had no treatment and CFU numbers were set $100 \%$. All data shows means \pm SD; experiments were performed in triplicate and repeated 3 times. One-way ANOVA showed no significant decrease in viability between any of the different conditions. 

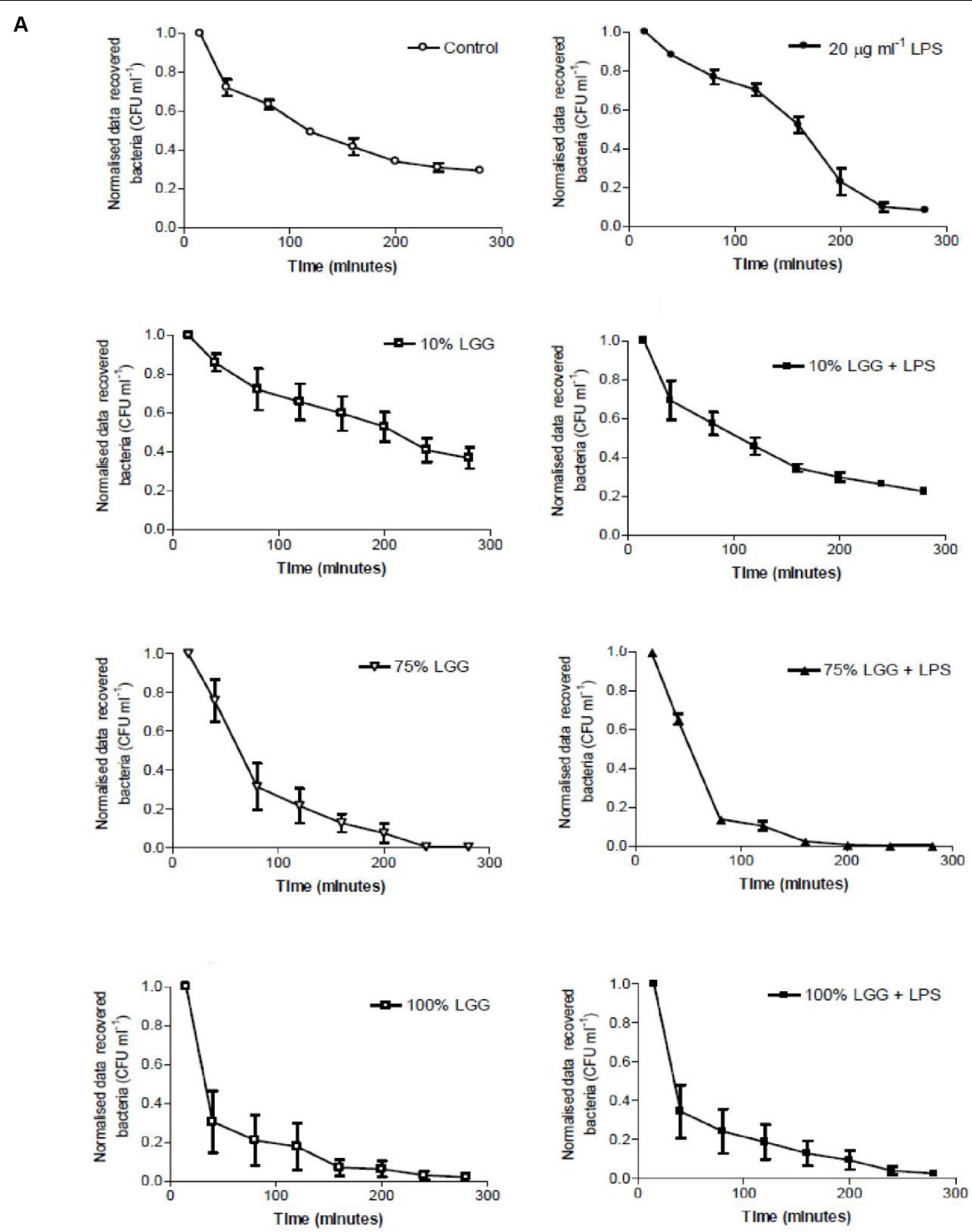

B

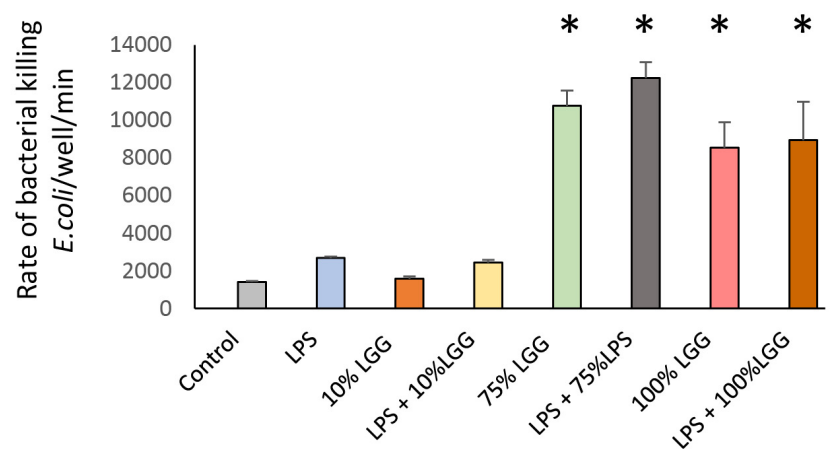

FIGURE 2 | Recovered intracellular E. coli bacteria from J774 macrophages during bacterial killing phase. (A) The graphs represent the number of bacterial colonies (CFU) recovered following gentamicin protection and were normalized by converting the starting CFU/mL to 1.0 in each condition. Data shows mean \pm SD; all experiments were performed in duplicate and repeated at least three times. (B) The rate of bacterial killing, determined as described in the materials and methods, presented in column graph format. Significant differences $(p<0.05)$ are shown with the asterisk. 
As the experiments in this study involved determining E. coli viability, the direct effects of LGG-CM on $E$. coli survival were also examined. E. coli cultures grown overnight were resuspended in LGG-CM and cultured for a further $6 \mathrm{~h}$ and $24 \mathrm{~h}$. In all cases, there was no significant adverse effects on $E$. coli growth $(p>0.05)$ at any of the LGG-CM concentrations tested suggesting that LGG-CM has no direct antibacterial effect on E. coli (Figure 1B).

\section{Macrophage Killing of E. coli Is Enhanced by Lactobacillus rhamnosus Conditioned Medium}

The effect of the LGG-CM on the rate of bacteria killing was monitored in macrophages, with intracellular E. coli recovered from the macrophages every $40 \mathrm{~min}$. To ensure that only intracellular bacteria were assessed, all extracellular bacteria were killed with gentamicin at $200 \mu \mathrm{g} / \mathrm{ml}$. As expected, the untreated controls showed a time-dependent reduction in bacterial viability over time (1400 \pm 59 bacteria killed/min; Figure 2). While $10 \%$ LGG-CM had no significant effect of the rate of bacterial killing (Figure 2; $p>0.05$ ), the kill rate dramatically increased almost 10 -fold following incubation in $75 \%$ or $100 \%$ LGG-CM, reaching over $12000 \pm 800 \mathrm{bacteria}$ killed/min). Therefore, the data strongly suggest that cell-free compounds released into the supernatant during LGG growth stimulate macrophages to kill E. coli.

To visualize the killed bacteria under the microscope, intracellular bacteria were stained with acridine orange/crystal violet to distinguish live from dead cells. The data shown in Figure 3, supported the killing curve data, and confirmed that macrophages treated with 75\% LGG-CM exhibited a clear increase in bacterial killing compared to controls.

\section{Effect of NO and ROS Inhibitors on Bacterial Digestion}

To identify the mechanisms involved in LGG-CM-stimulated macrophage bacterial killing, macrophages were incubated with inhibitors that are known to perturb different aspects of phagocytosis including L-NMMA, an inhibitor of the mammalian iNOS enzyme which catalyze the production of NO. In addition, cell-permeable variants of superoxide dismutase and catalase were used to scavenge free radicals. Apocyanin (Apo) which specifically inhibits NADPH oxidase that converts oxygen to superoxide radicals was also examined. As expected, all inhibitors suppressed bacterial killing in treated cells (Figure 4). Apo treatment resulted in a significant reduction in bacterial killing $(p<0.001)$ in both control cells and treated cells. However, the Apo treatment of LGG-CM treated cells (Figure 4A) did not return to the level of bacterial killing seen with the controls, suggesting LGG-CM stimulation of phagocytosis was multifactorial. This premise was suggested using the other inhibitors which demonstrated a similar trend (Figures 4BD). Taken together, the data collectively demonstrate that the stimulation of bacterial killing by LGG-CM involves different canonical phagocytic stages that are blocked by these compounds.

\section{Stimulation of NADPH Oxidase by LGG-Conditioned Medium}

To investigate the involvement of ROS in LGG-CM-stimulated macrophages further, Western blots were performed to visualise and quantify the relative expression of NADPH oxidase subunits gp91(phox) and p47(phox). Figure 5A shows densitometry data taken from the Western blots with a representative blot shown in Figure 5B. The data show untreated (control) levels of the protein significantly lower $(p<0.001)$ than LGG-CM-treated levels, consistent with an increased ability to kill bacteria, supporting our data. LPS and diluted samples of LGG-CM exhibited little effect on the expression of gp91 (phox) or P47 (phox). Taken together the Western blot data suggest an induction in NADPH expression, consistent with its role in bacterial killing.

\section{Visualization of ROS Production}

To further assess the role of ROS induction in LGG-CM-treated cells, we measured ROS production in real time within J774 murine macrophages pre-loaded with the fluorescent dye 2,7dichlorofluorescein diacetate (DCFDA; Figure 5C). Fluorescence was monitored every $2 \mathrm{~min}$ between 0 and $280 \mathrm{~min}$ to give a quantitative measure of intracellular ROS production. ROS production was stimulated when macrophages were exposed to the LGG-CM, with or without the addition of LPS (Figure 5C). LPS alone, or 10\% LGG-CM did not affect ROS production within the macrophages. Our data support the Western blot and bacterial killing data that ROS production is stimulated in macrophages by exposure to the LGG conditioned medium (Figure 5C), suggesting secreted components by Lactobacillus have the ability to stimulate ROS via NADPH oxidase activity.

The DCFDA data were further supported by microscopy (Figure 6). ROS production from cells treated with LGG-CM macrophages were first loaded with $\mathrm{H}_{2}$ DCFDA. Macrophages were exposed to different conditions including LGG-CM (10\% LGG and $75 \%$ LGG) and $20 \mu \mathrm{g} \mathrm{ml}^{-1}$ LPS and cells were visualized by fluorescence microscopy as described in the Methods section. To demonstrate the fluorescent dye, images were psudocolored (Figure 6) with blue representing the coolest fluorescent spot, followed by shades of green, yellow, orange, and red for brighter intensity. It was evident from the images that macrophages treated with 75\% LGG-CM demonstrated higher ROS production both at $30 \mathrm{~min}$ and $60 \mathrm{~min}$ compared to control, LPS treated or 10\% LGG-CM treated macrophages.

\section{Nitric Oxide Production by LGG-CM}

To determine whether LGG-CM regulated NO production, J774 macrophages were treated with the LGG-CM for $24 \mathrm{~h}$ prior to determining nitrite levels. Nitrite is an indirect measure for $\mathrm{NO}$ production. LPS was used as a positive control. LGG-CM caused a small, observable but not significant increase in nitrite levels above control at following $24 \mathrm{~h}$ of incubation. LPS on the other hand induced significant elevation in NO production at $24 \mathrm{~h}$ $(p<0.001$; Figure 7$)$.

Taken together these experiments demonstrate that while LGG-CM-induced bacterial killing is multifactorial, involving multiple phagocytic pathways, it is strongly linked with the 


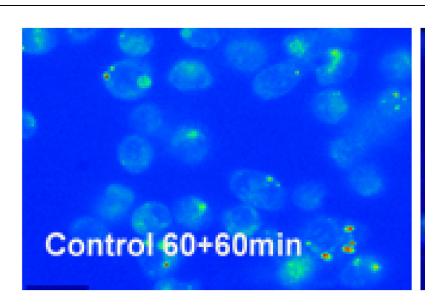

Control

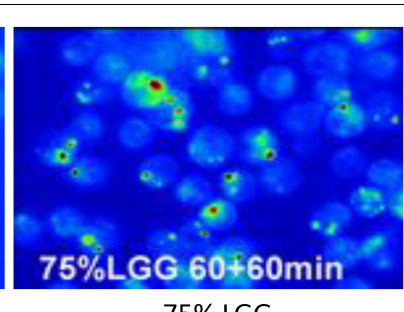

75\% LGG
FIGURE 3 | Killing of intracellular bacteria within $\mathbf{J 7 7 4}$ macrophages in the presence of LGG supernatant. Viable bacteria were observed following phagocytosis using acrdine orange and crystal violet staining assay. Microscopy images show control (left, no treatment), 75\% LGG (right image) and are presented as pseudo-colored fluorescence images at $60 \mathrm{~min}$ time points during the killing phase period. Viable bacteria are shown in green and dead bacteria are shown in red.

production of ROS through NADPH oxidase, with little significant input for NO production.

\section{DISCUSSION}

This study investigated the bacterial killing ability of the murine macrophage J774 cell line following exposure to different concentrations of cell-free conditioned medium from the probiotic bacterium L. rhamnosus GG (named LGG-CM). Cell free LGG-CM was used since it was shown to have immunomodulatory effect similar to live bacteria (Yan and Polk, 2012). This was also done to avoid interference of potential ingestion of the Lactobacillus bacteria by the macrophages. In this study, macrophages and E. coli were incubated for $60 \mathrm{~min}$ at a ratio of 1:50 which has been found to be essential to generate reproducible data in our study. The intracellular killing process was monitored for up to 280 min post incubation period, since phagocytic death of ingested bacteria takes approximately 2 to $4 \mathrm{~h}$ post ingestion (Levitz et al., 1986; Michaliszyn et al., 1995; Hacker et al., 2002; Philippe et al., 2003; Kirschnek et al., 2005). The rate of decrease in the total number of bacteria recovered during the post-incubation bacterial digestion period from the macrophages was used as a measure of the rate of intracellular killing.

Bacterial killing in macrophage occurs in the phagosomes. Fundamental changes in the acute chemical composition of phagosomes, and their subsequent fusion with endosomes, and lysosomes creates an environment, which becomes a highly acidic, oxidative and degradative milieu for killing of bacteria. During phagosome maturation, the phagosomes develop into a phagolysosome within which a range of antibacterial compounds such as antimicrobial peptides and reactive free radicals including ROS and NO are generated (Flannagan et al., 2009). These biochemical processes may take from several minutes to few hours depending upon the bacterial strain and the type of phagocytes such as neutrophils or macrophages (Nusse, 2011).

Regarding the experimental design of our study, there are several points that should be considered. The killing of bacteria in steadily maturing phagolysosomes could have an impact on viable bacterial cell recovery. In our experiments, the number of E. coli recovered from the control and LGG-CM-treated macrophages at $60 \mathrm{~min}$ was identical to the number of $E$. coli recovered at $30 \mathrm{~min}$ time points for both control and LGGCM treatments, suggesting a limited bacterial killing occurs within the first $1 \mathrm{~h}$ of incubation period. Similar results were reported previously (Vincenti, 2010). Thus, in all experiments in this study, phagocytosis assays were performed following a 60-min incubation period. While our experiments also used a non-pathogenic species of $E$. coli, we accept that the role of phagocytosis against non-pathogens may be different as it would involve pathogenic strategies that we have not tested in the present study. Another caveat of this study is that the effect of LGG-CM on the killing of Lactobacillus bacteria itself is not studied. We envisage that components secreted by the Lactobacillus would be acting in-trans, with little access of the macrophage to the probiotic strain. We should also acknowledge that E. coli, like other species of bacteria, have ROS or NO evasion and defensive strategies that may impact the findings of this study. Thus, while our data report on bacterial killing, the defensive strategy of the bacterial species being tested has not been considered and may impact the elucidation of the mechanism involved. Finally, in this study we have used chemical inhibitors to provide information of the pathways that might be involved in LGG-CM stimulation of bacterial killing. However, we accept that inhibitors may have a variety of off-target effects and for this reason, we supported the inhibitor studies with Western blot analysis and in-cell monitoring of ROS.

Certain probiotic supernatants have previously been shown to have antibacterial properties on a number of bacterial species. This effect was suggested to be due to low $\mathrm{pH}$ of the supernatant (Tejero-Sariñena et al., 2012). This effect was found to be negated by neutralizing the $\mathrm{pH}$. Additionally, in our study, probiotic conditioned media from $L$. rhamnosus had no direct antibacterial effect on the E. coli species we used in the study for up to $24 \mathrm{~h}$. In contrast, when incubated with J774 macrophages, LGG-CM enhanced the rate of bacterial killing caused by macrophages. This was very much dependent on the concentration of LGGCM used with $75 \%$ or $100 \%$ of the conditioned medium causing six times more E. coli killing. The increased rate of E. coli killing was found to be associated with the enhanced ROS production induced by LGG-CM in J774 macrophages.

The role of ROS in bacterial killing has previously been emphasized by the finding that it can attack both extracytoplasmic or cytoplasmic targets (in particular iron-sulfur cluster- containing proteins and DNA; Craig and Slauch, 2009). The increase in ROS production in response to LGG-CM in our studies was associated with the activation of NADPH oxidase as shown by Western Blot. In phagocytes, NADPH oxidase dependant ROS production is known to be crucial for microbial killing; however, excessive ROS production induces tissue injury and prolonged inflammatory reactions that contribute to inflammatory diseases. Thus, NADPH oxidase activation must be tightly regulated to limit ROS production.

Phosphorylation of $\mathrm{p} 47^{\text {phox }}$ is essential for NADPH oxidase activation in phagocytes such as neutrophils (Li and Shah, 2004) 
A
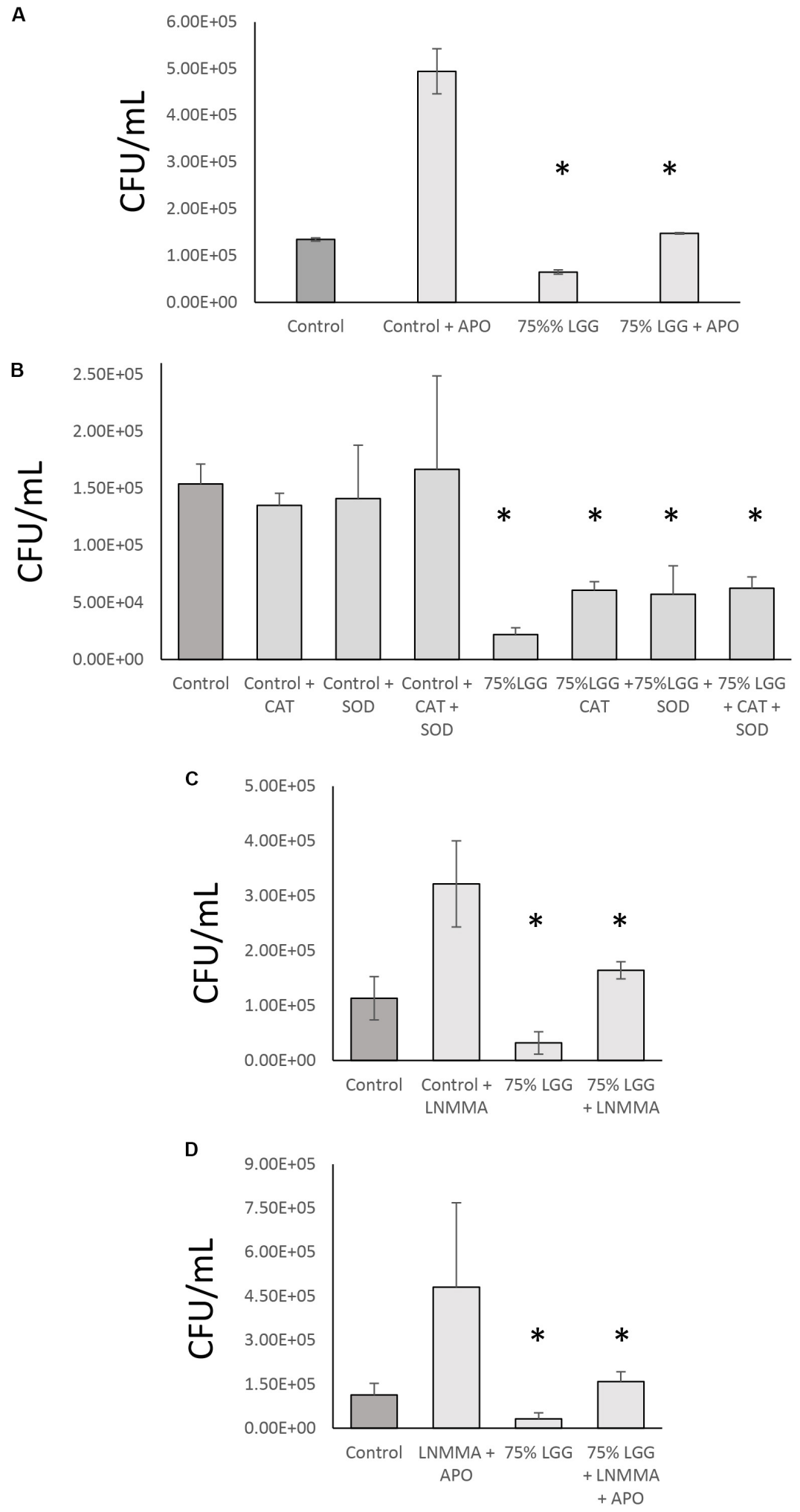

FIGURE 4 | Role of NO and ROS inhibitor combination in bacterial digestion in the presence of LGG-CM. The effect of iNOS + NADPH oxidase inhibitors on bacterial digestion were investigated in the presence of LGG-CM. The inhibitors used were Apocyanin (Apo) = NADPH oxidase inhibitor (A); Cell permeable variants of SOD and Catalase that scavenge reactive oxygen species (B). LNMMA = iNOS inhibitor (C). A combination of LNMMA and Apocyanin were used in (D). Experiments were performed in duplicate and repeated three times. Error bars indicate \pm standard error of the mean. Statistical analysis was carried out using Graph Pad Prism 3. The Dunnett's multiple comparison post-hoc tests was performed after observing a significant difference from One way ANOVA. An asterisk (*) indicates significant difference $(p<0.01)$ between the treatments and control. 
A

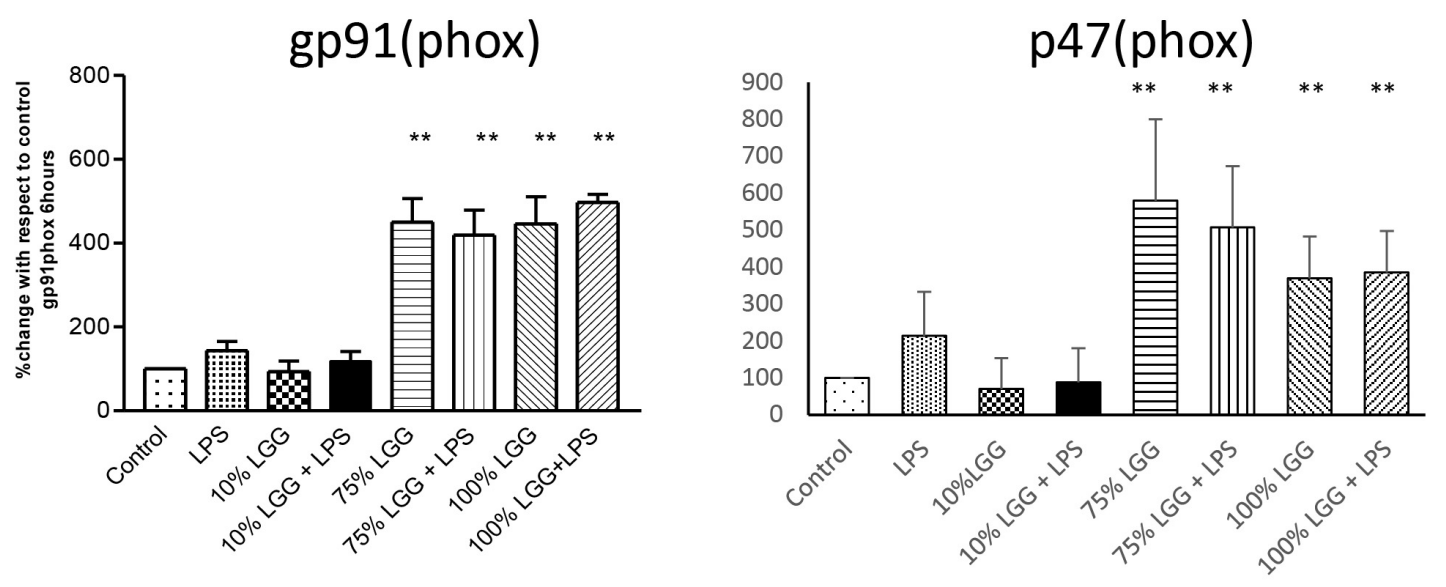

B

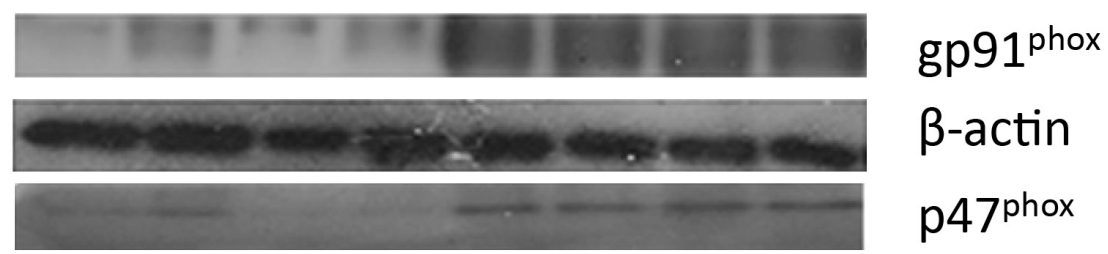

C

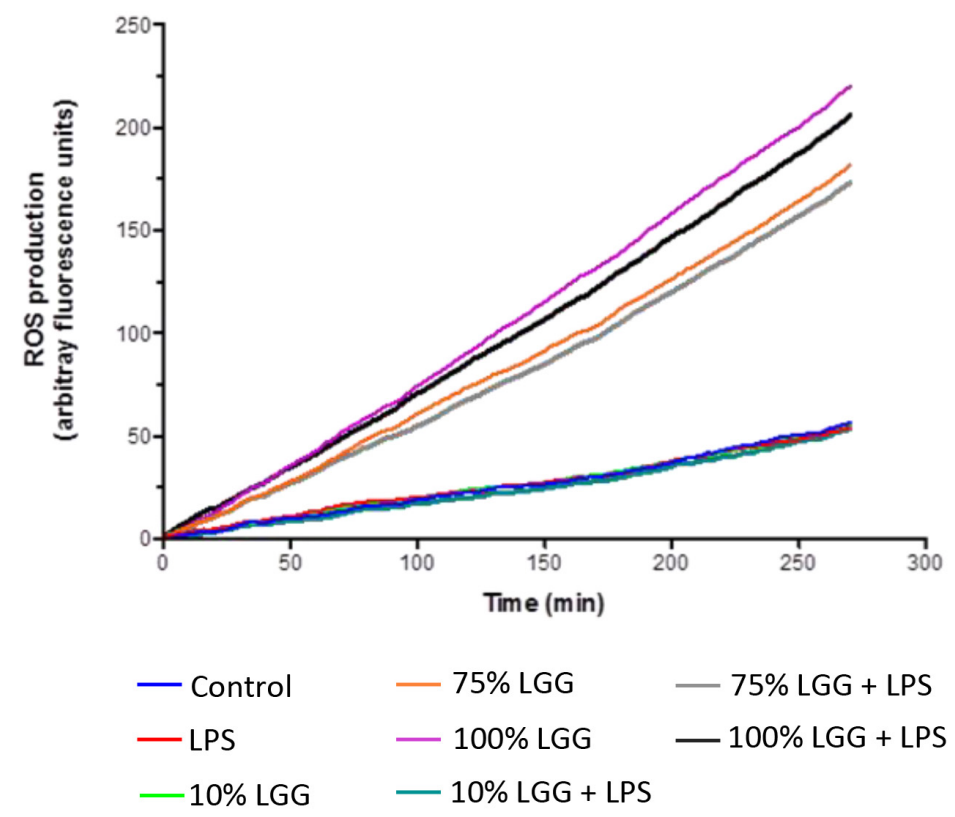

FIGURE 5 | Effect of LGG-CM on reactive oxygen species induction. (A) Protein levels of the NADPH components p46(phox) and gp91(phox) were visualized and quantified by Western blot analysis as shown in (B). Band quantitation of 3 independent experiments was performed by densitometry using Image J. Data shows relative protein levels with respect to the control; shown are means \pm standard error of 3 independent experiments. A double asterisk $\left.{ }^{(*)}\right)$ indicates a significant difference compared with the control $(p<0.01$ ). (C) ROS production measured in real-time (between 0 and $280 \mathrm{~min}$ ) by fluorescence using a ROS indictor dye DCFDA. The relative level of fluorescence is shown for each treatment given in the key. 
A
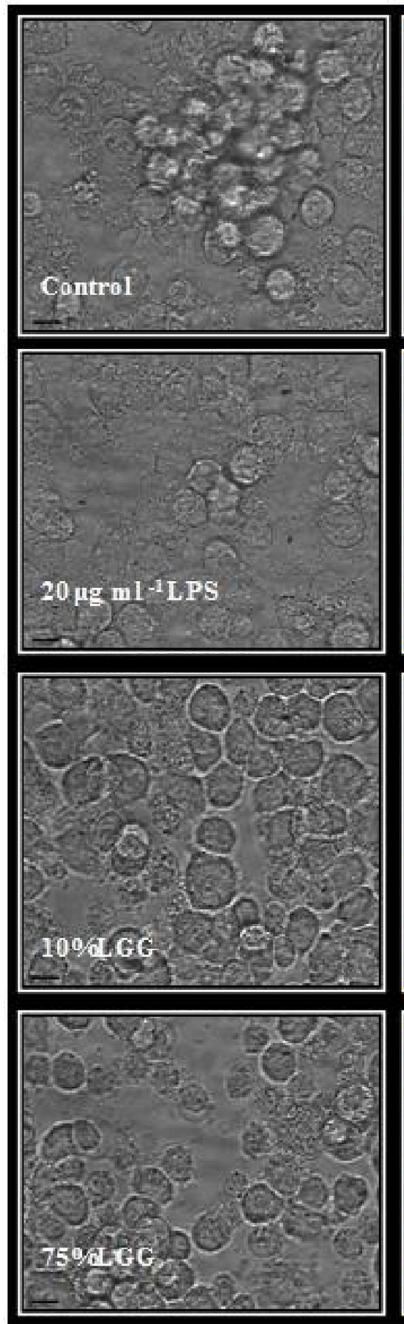

B
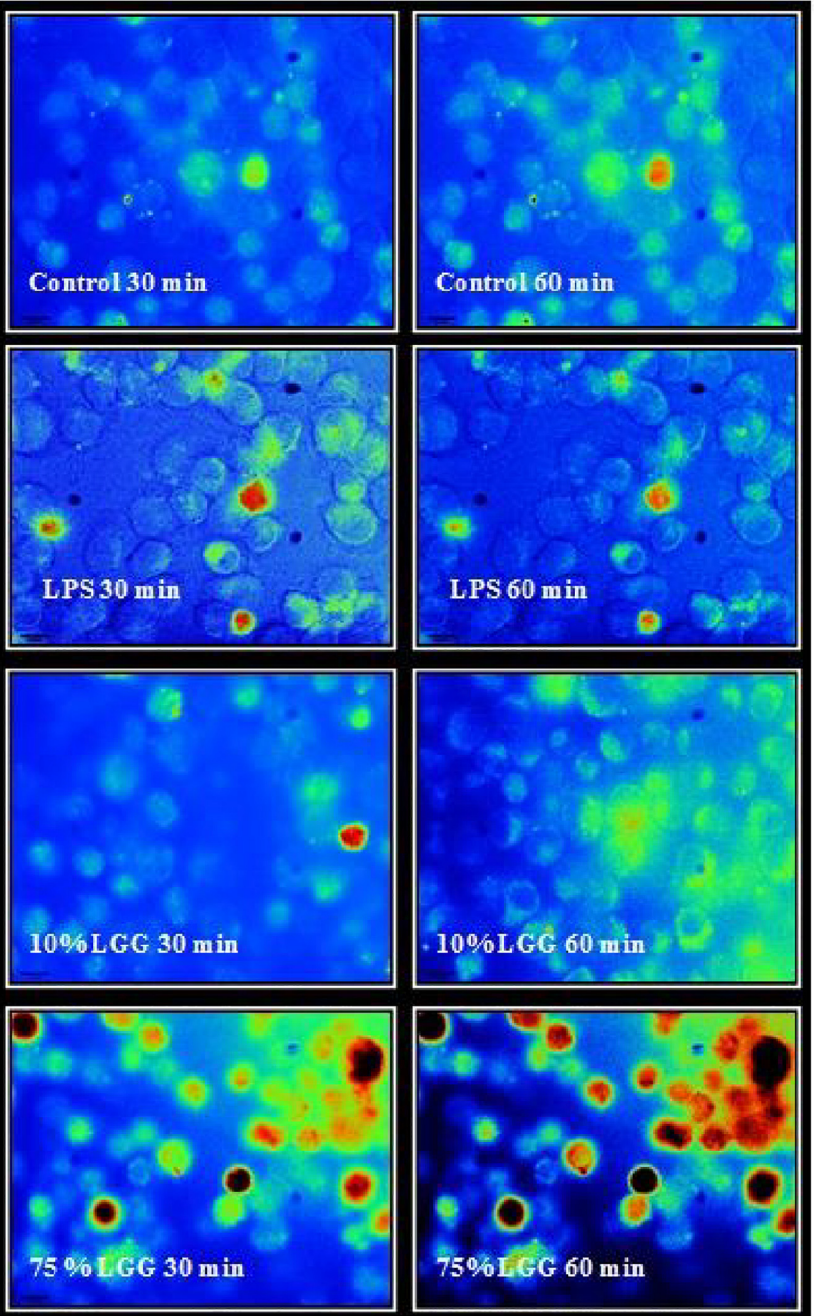
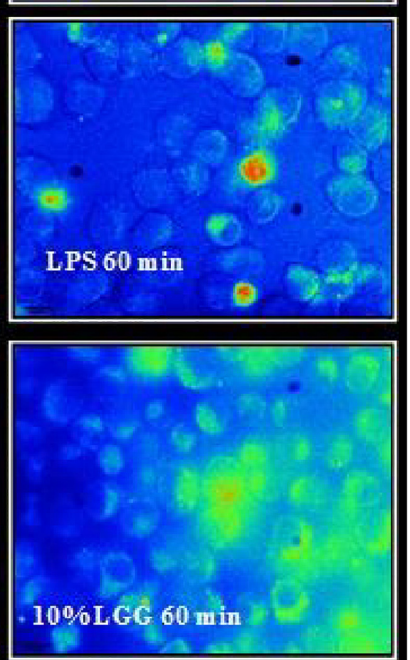

C

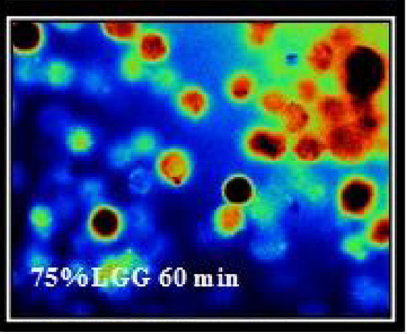

FIGURE 6 | Fluorescence microscopy imaging of ROS production in macophages. The macrophages were labeled with $\mathrm{H}_{2} \mathrm{DCFDA}$ and treated with $20 \mu \mathrm{g} \mathrm{ml}^{-1}$ LPS, $10 \%$ LGG-CM, and $75 \%$ LGG-CM for 30 and 60 min. The images are representative of one of the three experiments performed. The vertical panels illustrate adjacently placed bright field $\mathbf{( A )}$ and pseudo colored fluorescence images $\mathbf{( B , C ) . ~ F l u r o e s c e n c e ~ c o r r e s p o n d s ~ t o ~ a ~ h e a t ~ m a p , ~ b l u e ~}=$ low, and red $=$ high.

and unphosphorylated $4^{\text {phox }}$ has been shown to have inhibitory effects on NADPH oxidase activity (Ray and Shah, 2005). Phosphorylation of $\mathrm{p} 47^{\text {phox }}$ has been shown to relieve these inhibitory effects and at the same time increased NADPH oxidase activity by binding to membrane bound gp91 ${ }^{\text {phox }}$ (Belambri et al., 2018). In the present study, NADPH oxidase subunits gp91 $1^{\text {phox }}$ and $4^{\text {phox }}$ were measured at different time points. We did not observe any significant changes in the gp91 phox and $\mathrm{p} 47^{\text {phox }}$ expression in the first $2 \mathrm{~h}$ of incubation with LGG-CM treatments (data not shown); whereas at $6 \mathrm{~h}$ of incubation, LGG-CM treated macrophages showed a significant increase in the expression of gp91phox and $\mathrm{p} 47^{\text {phox }}$ compared to untreated macrophages. This is in line with the findings from previous studies that NADPH oxidase activation occurs over the short term through phosphorylation of the enzyme subunits and over the long term by increased subunit expression (Li and Shah, 2004).

Recent findings demonstrated that LGG-CM is capable of stimulating a differential rate of ROS production from macrophages during the ingestion period and the digestion period. When macrophages were treated with a higher concentration of LGG-CM, the ROS production rate during the first hour of treatment was approximately 2 times higher than the ROS production rate during the next $280 \mathrm{~min}$. LGG-CM mediated ROS production in the macrophages appears to be oscillatory (Nanjundaiah et al., 2016). This sort of ROS regulation has been previously demonstrated in plant root hairs and guard cells and also during pollen stigma interactions (McInnis et al., 2006; Monshausen et al., 2007; Takeda et al., 


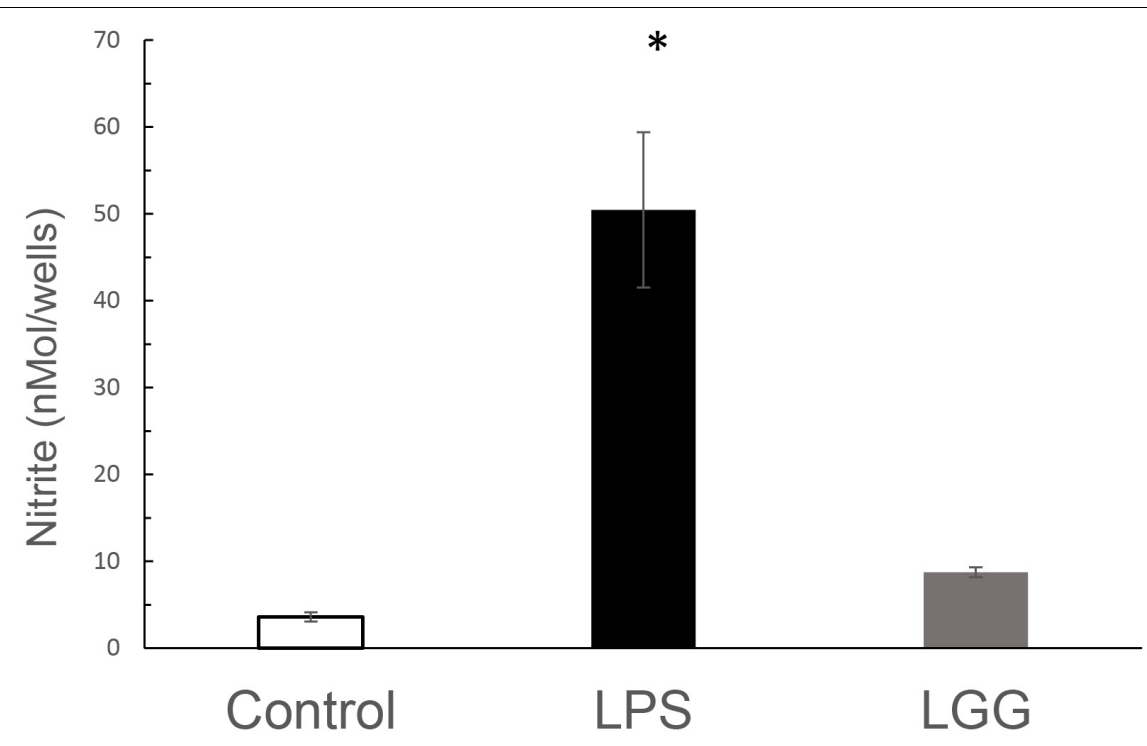

FIGURE 7 | The effect of LGG-CM and LPS on NO production from J774 macrophages. Macrophages were treated with LGG-CM and LPS (1 $\mu \mathrm{g}$ ml ${ }^{-1}$ ). Accumulated nitrite was measured by Griess assay after $24 \mathrm{~h}$. Results are the mean of 5 separate experiments performed in triplicate. Error bars indicate \pm standard error of the mean. Statistical analysis was performed using one-way ANOVA followed by Dunnett multiple comparison test. Asterisk shows significance at $p<0.05$.

2008; Jammes et al., 2009). Detection of the oscillating pattern of ROS signals in plants clearly supports our current findings where our raw data for free radical production demonstrates an oscillatory pattern (not shown). This oscillatory pattern of ROS production in macrophage to LGG-CM may play a role in maintaining a nontoxic steady-state level of ROS, while allowing for the transient accumulation of ROS in particular subcellular locations. This pattern of ROS production may have a physiological significance and could act as signals (Mittler et al., 2004). In this study, the LGG-CM may activate macrophages to kill microbes through the production of ROS and perhaps through modulation of NO. This phenomenon might have physiological importance in shifting its immune function from degrading debris from tissues to killing invading microbes to present antigen to $T$ cells.

In this study, although LPS has been shown to produce substantial levels of NO, it was found to have little effect on the bacterial killing process. Such data is inconsistent with some studies but clearly supported by others (Michlewska et al., 2009; Feng et al., 2011; Kapellos et al., 2016), suggesting different experimental design may be responsible for these different outcomes. On the other hand, LGG-CM has increased bacterial killing which was around three times faster than the LPS treatment despite inducing little NO when compared to LPS. It is worth noting, however, that NO has been shown to play an essential role in the anti-microbial and tumouricidal activity of murine macrophages (Netea-Maier et al., 2018; Ramachandran et al., 2018). NO, formed from arginine by nitric oxide synthases (iNOS), and its downstream reactive nitrogen intermediates (RNIs) are toxic to microbes and host cells via cysteine S-nitrosation of proteins, deamination of nucleic acids, and desaturation of lipids (Nathan and Cunningham-Bussel, 2013). There is evidence that reduction NO does not interfere with macrophage phagocytosis (Miyashita et al., 2018). This is inconsistent with our study using pharmacological inhibition of NO production with L-NMMA which was found to reduce bacterial killing, although, increase production of NO with LPS had no effect on bacterial killing mechanism. In our study probiotic conditioned medium seems to skew the balance of ROS and NO production via a complex and poorly understood mechanism.

In conclusion, we found that the bacterium LGG releases components during cell culture which enhances bacterial killing by macrophages, associated with increased generation of ROS via activation of NADPH oxidase. Small increases in NO may also have a role in the bacterial killing mechanism, however, it is probably a beneficial mechanism for probiotic bacterial to protect the host as excessive generation of NO can cause tissue damage. This is first report that shows the differential regulation of ROS and NO by probiotic bacteria on bacterial killing mechanism(s) by macrophages and this may have clinical importance in maintaining intestinal homeostasis.

\section{DATA AVAILABILITY STATEMENT}

The raw data supporting the conclusions of this article will be made available by the authors, without undue reservation.

\section{AUTHOR CONTRIBUTIONS}

YN performed the experiments and analyzed the data. MS designed the study, analyzed the data, and drafted the article. DW designed the study. $\mathrm{ZA}$ and $\mathrm{AB}$ reviewed the article. $\mathrm{ZK}$ performed the study design and reviewed the article. All authors contributed to the article and approved the submitted version. 


\section{REFERENCES}

Belambri, S. A., Rolas, L., Raad, H., Hurtado-Nedelec, M., My-Chan Dang, M.C., and El-Benna, J. (2018). NADPH oxidase activation in neutrophils: role of thephosphorylation of its subunits. Eur. J. Clin. Invest. 48(Suppl. 2):e12951. doi: 10.1111/eci.12951

Berman, S. H., Eichelsdoerfer, P., Yim, D., Elmer, G. W., and Wenner, C. A. (2006). Daily ingestion of a nutritional probiotic supplement enhances innate immune function in healthy adults. Nutr. Res. 26, 454-459. doi: 10.1016/j.nutres.2006. 08.002

Craig, M., and Slauch, J. M. (2009). Phagocytic superoxide specifically damages an extracytoplasmic target to inhibit or kill Salmonella. PLoS One 4:e4975. doi: 10.1371/journal.pone.0004975

Donnet-Hughes, A., Rochat, F., Serrant, P., Aeschlimann, J. M., and Schiffrin, E. J. (1999). Modulation of nonspecific mechanisms of defense by lactic acid bacteria: effective dose. J. Dairy Sci. 82, 863-869. doi: 10.3168/jds.s00220302(99)75304-X

Feng, X., Deng, T., Zhang, Y., Su, S., Wei, C., and Han, D. (2011). Lipopolysaccharide inhibits macrophage phagocytosis of apoptotic neutrophils by regulating the production of tumour necrosis factor $\alpha$ and growth arrestspecific gene 6. Immunology 132, 287-295. doi: 10.1111/j.1365-2567.2010. 03364

Flannagan, R. S., Cosio, G., and Grinstein, S. (2009). Antimicrobial mechanisms of phagocytes and bacterial evasion strategies. Nat. Rev. Microbiol. 7, 355-366. doi: $10.1038 /$ nrmicro 2128

Galdeano, C., Nunez, I. N., de LeBlanc, A. D., Carmuega, E., Weill, R., and Perdigon, G. (2011). Impact of a probiotic fermented milk in the gut ecosystem and in the systemic immunity using a non-severe protein energy malnutrition model in mice. Biomed. Central Gastroenterol. 11, 1-14.

Gill, H. S., Rutherfurd, K. J., Cross, M. L., and Gopal, P. K. (2001). Enhancement of immunity in the elderly by dietary supplementation with the probiotic Bifidobactedum lactis HN019. Am. J. Clin. Nutr. 74, 833-839. doi: 10.1093/ajcn/ 74.6 .833

Hacker, H., Furmann, C., Wagner, H., and Hacker, G. (2002). Caspase $-9 /-3$ activation and apoptosis are induced in mouse macrophages upon ingestion and digestion of Escherichia coli bacteria. J. Immunol. 169, 3172-3179. doi: 10.4049/jimmunol.169.6.3172

Jammes, F., Song, C., Shin, D., Munemasa, S., Takeda, K., Gu, D., et al. (2009). MAP kinases MPK9 and MPK12 are preferentially expressed in guard cells and positively regulate ROS-mediated ABA signalling. Proc. Natl. Acad. Sci. U.S.A. 106, 20520-20525. doi: 10.1073/pnas.0907205106

Kaila, M., Isolauri, E., Soppi, E., Virtanen, E., Laine, S., and Arvilommi, H. (1992). Enhancement of the circulating antibody secreting cell response in human diarrhoea by a human Lactobacillus strain. Pediatr. Res. 32, 141-144. doi: 10.1203/00006450-199208000-00002

Kapellos, T. S., Taylor, L., Lee, H., Cowley, S. A., James, W. S., Iqbal, A. J., et al. (2016). A novel real time imaging platform to quantify macrophage phagocytosis. Biochem. Pharmacol. 116, 107-119. doi: 10.1016/j.bcp.2016.07. 011

Kirschnek, S., Ying, S., Fischer, S. F., Hacker, H., Villunger, A., Hochrein, H., et al. (2005). Phagocytosis induced apoptosis in macrophages is mediated by upregulation and activation of the Bcl-2 homology domain 3-only protein Bim. J. Immunol. 174, 671-679. doi: 10.4049/jimmunol.174.2.671

Kotzamandis, C., Kourelis, A., Litopoulou-Tzanetaki, E., Tzanetakis, N., and Yiangou, M. (2010). Evaluation of adhesion capacity, cell surface traits and immunomodulatory activity of presumptive probiotic Lactobacillus strains. Intern. J. Food Microbiol. 140, 154-163. doi: 10.1016/j.ijfoodmicro.2010.04.004

Levitz, S. M., Selsted, M. E., Ganz, T., Lehrer, R. I., and Diamond, R. D. (1986). In vitro killing of spores and hyphae of Aspergillus fumigatus and Rhizopus oryzae by rabbit neutrophil cationic peptides and bronchoalveolar macrophages. J. Infect. Dis. 154, 483-489. doi: 10.1093/infdis/154.3.483

Li, J. M., and Shah, A. M. (2004). Endothelial cell superoxide generation: regulation and relevance for cardiovascular pathophysiology. Am. J. Physiol. Regul. Integr. Comparat. Physiol. 287, R1014-R1030.

Marranzino, G., Villena, J., Salva, S., and Alvarez, S. (2012). Stimulation of macrophages by immunobiotic Lactobacillus strains: influence beyond the intestinal tract. Microbiol. Immunol. 56, 771-781. doi: 10.1111/j.1348-0421. 2012.00495.x
McInnis, S. M., Desikan, R., Hancock, J. T., and Hiscock, S. J. (2006). Production of reactive oxygen species by angiosperm stigmas and pollen: potential signalling crosstalk? New Phytol. 172, 221-228. doi: 10.1111/j.1469-8137.2006.01 875.x

Michaliszyn, E., Senechal, S., Martel, P., and de Repentigny, L. (1995). Lack of involvement of nitric oxide in killing of Aspergillus fumigatus conidia by pulmonary alveolar macrophages. Infect. Immunol. 63, 2075-2078. doi: 10. 1128/iai.63.5.2075-2078.1995

Michlewska, S., Dransfield, I., Megson, I. L., and Rossi, A. G. (2009). Macrophage phagocytosis of apoptotic neutrophils is critically regulated by the opposing actions of pro-inflammatory and anti-inflammatory agents: key role for TNFalpha. FASEB J. 23, 844-854. doi: 10.1096/fj.08-121228

Mittler, R., Vanderauwera, S., Gollery, M., and Breusegem, F. V. (2004). Reactive oxygen gene network of plants. Trends Plant Sci. 9, 490-498. doi: 10.1016/j. tplants.2004.08.009

Miyashita, T., Minami, K., Ito, M., Koizumi, R., Sagane, Y., Watanabe, T., et al. (2018). Emu Oil reduces LPS-induced production of nitric oxide and TNFbut not phagocytosis in RAW 264 macrophages. J. Oleo Sci. 67, 471-477. doi: 10.5650/jos.ess 17228

Monshausen, G. B., Bibikova, T. N., Messerli, M. A., Shi, C., and Gilroy, S. (2007). Oscillations in extracellular $\mathrm{pH}$ and reactive oxygen species modulate tip growth of Arabidopsis root hairs. Proc. Natl. Acad. Sci. 104, 20996-21001. doi: 10.1073/pnas.0708586104

Nanjundaiah, Y. S., Wright, D. A., Baydoun, A. R., O’Hare, W. T., Ali, Z., Khaled, Z., et al. (2016). Lactobacillus rhamnosus GG conditioned media modulates acute reactive oxygen species and nitric oxide in J774 murine macrophages. Biochem. Biophys. Rep. 6, 68-75. doi: 10.1016/j.bbrep.2016.03.003

Nathan, C., and Cunningham-Bussel, A. (2013). Beyond oxidative stress: an immunologist's guide to reactive oxygen species. Nat. Rev. Immunol. 13, 349361. doi: $10.1038 /$ nri3423

Netea-Maier, R. T., Smit, J. W. A., and Netea, M. G. (2018). Metabolic changes in tumor cells and tumor-associated macrophages: a mutual relationship. Cancer Lett. 413, 102-109. doi: 10.1016/j.canlet.2017.10.037

Nixon, A. F., Cunningham, S. J., Cohen, H. W., and Crain, E. F. (2012). The effect of Lactobacillus GG on acute diarrheal illness in the pediatric emergency department. Pediatr. Emerg. Care. 28, 1048-1051. doi: 10.1097/PEC. 0b013e31826cad9f

Nusse, O. (2011). Biochemistry of the phagosome: the challenge to study a transient organelle. Sci. World J. 11, 2364-2381. doi: 10.1100/2011/741046

Pelto, L., Isolauri, E., Lilius, E., Nuutila, J., and Salminen, S. (1998). Probiotic bacteria down-regulate the milk-induced inflammatory response in milkhypersensitive subjects but have an immunostimulatory effect in healthy subjects. Clin. Exper. Allerg. 28, 1474-1479. doi: 10.1046/j.1365-2222.1998. 00449.x

Philippe, B., Ibrahim-Granet, O., Prevost, M. C., Gougerot-Pocidalo, M. A., Sanchez Perez, M., Van der Meeren, A., et al. (2003). Killing of Aspergillus fumigatus by alveolar macrophages is mediated by reactive oxidant intermediates. Infect. Immun. 71, 3034-3042. doi: 10.1128/iai.71.6.3034-3042.2003

Ramachandran, R. A., Lupfer, C., and Zaki, H. (2018). The inflammasome: regulation of nitric oxide and antimicrobial host defence. Adv. Microb. Physiol. 72, 65-115. doi: 10.1016/bs.ampbs.2018.01.004

Ray, R., and Shah, A. M. (2005). NADPH oxidase and endothelial cell function. Clin. Sci. 109, 217-226. doi: 10.1042/cs20050067

Rudin, A., and Lundell, A. C. (2012). Infant B cell memory and gut bacterial colonization. Gut Microb. 3, 474-475. doi: 10.4161/gmic.21419

Sun, J., Zhang, X., Broderick, M., and Fein, H. (2003). Measurement of nitric oxide production in biological systems by using griess reaction assay. Sensors 3, 276-284. doi: 10.3390/s30800276

Takao, S., Smith, E. H., Wang, D., Ciian, C. K., Bulkley, G. B., and Klein, A. S. (1996). Role of reactive oxygen metabolites in murine peritoneal macrophage phagocytosis and phagocytic killing. Am. J. Physiol. Cell Physiol. 271, C1278C1284.

Takeda, S., Gapper, C., Kaya, H., Bell, E., Kuchitsu, K., and Dolan, L. (2008). Local positive feedback regulation determines cell shape in root hair cells. Science 319, 1241-1244. doi: 10.1126/science.1152505

Tejero-Sariñena, S., Barlowb, J., Costabile, A., Gibson, G. R., and Rowland, I. (2012). A pathogenesis and toxins in vitro evaluation of the antimicrobial 
activity of a range of probiotics against pathogens: evidence for the effects of organic acids. Anaerobe 18, 530-538. doi: 10.1016/j.anaerobe.2012.08.004

Villena, J., and Kitazawa, H. (2014). Modulation of intestinal TLR4-inflammatory signalling pathways by probiotic microorganisms: lessons learned from Lactobacillus jensenii TL2937. Front. Immunol. 4:512. doi: 10.3389/fimmu.2013. 00512

Vincenti, J. E. (2010). The influence of cell free Lactobacillus rhamnosus GG supernatant on the phagocytic activity of macrophages. Biosci. Horiz. 3, 105112. doi: 10.1093/biohorizons/hzq014

Yan, F., and Polk, D. B. (2002). Probiotic bacterium prevents cytokine-induced apoptosis in intestinal epithelial cells. J. Biol. Chem. 277, 50959-50965. doi: 10.1074/jbc.m207050200

Yan, F., and Polk, D. B. (2012). Characterization of a probiotic-derived soluble protein which reveals a mechanism of preventive and treatment effects of probiotics on intestinal inflammatory diseases. Gut Microb. 3, 25-28. doi: 10.4161/gmic. 19245
Yoda, K., He, F., Miyazawa, K., Hiramatsu, M., and Yan, F. (2012). Fermented milk containing Lactobacillus GG alleviated DSS-induced colitis in mice and activated epidermal growth factor receptor and Akt signalling in intestinal epithelial cells. Microb. Ecol. Health Dis. 23:18586.

Conflict of Interest: The authors declare that the research was conducted in the absence of any commercial or financial relationships that could be construed as a potential conflict of interest.

Copyright (c) 2020 Nanjundaiah, Wright, Baydoun, Khaled, Ali, Dean and Sarker. This is an open-access article distributed under the terms of the Creative Commons Attribution License (CC BY). The use, distribution or reproduction in other forums is permitted, provided the original author(s) and the copyright owner(s) are credited and that the original publication in this journal is cited, in accordance with accepted academic practice. No use, distribution or reproduction is permitted which does not comply with these terms. 